\title{
Bogdan Olaru \\ 2 Bypassing Morality Through Conventional and Unconventional Forms of Moral Enhancement
}

\subsection{The argument emanating from similarity}

After vigorous promotion of moral bioenhancement (Douglas 2008, 2013; Persson and Savulescu 2008, 2013, 2016; DeGrazia 2014), its prospect has encountered much criticism (Harris 2011, 2014, 2016; Schaefer 2015; Focquaert and Schermer 2015). Moral bioenhancement refers broadly to the idea that we should use biomedical means, if available and safe, to extend or supplement the efforts of bettering our moral nature. These new means work directly on the biological level of emotions, motivations, and attitudes. While serving the same aim of ameliorating human interactions from a moral point of view, such direct and unconventional tools are expected to catch up with more traditional and indirect means of moral enhancement, such as education, socialization, parental supervision, wise public policy, as well as classical tools of fostering reason and decision-making, such as advancing knowledge and spreading reliable information. Moral bioenhancement supplements this repertoire of wellestablished means, helps strengthen morality, and is in the service of a better world. However, one of the most important objections against moral bioenhancement (Harris 2011) is that manipulations of human functioning at the biochemical or neuronal level undercut a person's freedom and moral reasoning. Because of deeprooted connections between reason, autonomy, and morality, praised by many philosophers, this criticism amounted to exposing a self-defeating feature of any attempt of what might be qualified as moral bioenhancement. If, as the proponents assume, the new envisioned techniques focus on suppressing or increasing the biological layer of emotions, motivations, and/or attitudes to shift the behavioral output in the right direction, the change into a better person seems to occur in ways that are at least dissociated from, if not at odds with, rational scrutiny and moral agency. In other words, enhancing morality through biotechnological means seems to obliterate a hard-to-avoid relation between the idea of morality and moral person on the one hand and reason and justification on the other. As John Harris puts it, "The intervention is designed to bypass reasoning and act directly on attitudes. When such attitudes are manipulated, not only is freedom subverted but also morality is bypassed." (Harris 2014, 372) A fundamental flaw lies at the heart of any attempt at moral bioenhancement: it can only take place in a manner that threatens to erode, generally and in the long term, the very idea of morality. Moral bioenhancement thus falls short of reaching the aim of supporting and safeguarding morality itself. 
Is such a threat a new entry in ethics? And does it amount to a clear-cut distinction between conventional (i.e., through education and public policy) and unconventional (mainly via biochemical and neurological input) moral enhancement? John Harris, who acknowledges the distinction (Harris 2011, 104), exposes the risks that might arise with new forms of moral bioenhancement, but these risks are by no means unmatched by the painful, everyday pitfalls that occur during socialization, schooling, and parental education. This observation, which was mostly put forward by supporters of moral bioenhancement, underlines the similarity between new and old methods in order to gain public consent for novel enhancement techniques. For instance, when DeGrazia (2014) tackles the common objection against moral bioenhancement about the content of morality - skepticism that stems from moral pluralism - he argues that similar strain is put on our education system: "One should not inculcate moral values that are wrong, so how can a parent be sure that she or he is justified in providing a particular type of moral instruction? Also facing this challenge are public school teachers who attempt to inculcate in students certain moral virtues such as civility, respect for differences and concern for the poor." (DeGrazia 2014, 363) He recommends that we should stick with what he calls "points of overlapping consensus among competing, reasonable moral perspectives" (DeGrazia 2014, 364). The rule holds for both conventional moral enhancement and for whatever biomedical means of moral improvement will be considered appropriate by the state to support, encourage, or even require. There is one notable difference between what parents do when raising their children and what the state can be allowed to promote as better public policy. Parents enjoy more freedom to choose their view about what morality requires, whereas the state must check and approve any proposal of public moral enhancement against the content reached through overlapping consensus. Consequently, it should be easier to accept a public policy about a certain type of moral bioenhancement once the test of "overlapping consensus among competing, reasonable moral perspectives" (DeGrazia 2014, 364) is completed. In contrast, because of a broader area of disagreement, which is socially accepted when it comes to raising children, some might never totally get rid of a good portion of emotional discomfort caused by the fact that parents enjoy such significant power over how they morally shape their offspring. Their task is apparently more exposed to failures than a state-driven, robust research based on shared moral values. DeGrazia's argument depends on whether or not it is possible to reach a consensus on substantive matters that could express something vital for each reasonable moral view publicly endorsed in a liberal society and that could satisfy reasonable concerns about other competing views. This matter is far from being settled.

Mark Walker (2009) draws on the same idea of similarity when discussing what he labeled “The Genetic Virtue Project” (GVP) - an interdisciplinary project between philosophers, psychologists, and geneticists aimed at morally improving humankind through biotechnological manipulations of something that he assumes to be "genetic correlates of virtuous behavior." On the one hand, there are good reasons to directly 
target an individual's behavior, if the aim is to enhance his or her conformity with morality. But, on the other hand, GVP aims at more complex and stable interventions. GVP could emulate through genetic modifications what we actually welcome in parenting: promoting virtues as a way to enhance children's morality. Moreover, the intervention would be so profound that it could be passed on to the next generations. Thus, Walker draws his argument on the analogy between promoting virtue in common ethical practice and the project of genetically selecting for virtue-compatible features: "There is a tendency to think of the virtues being implemented on the knees of parents but this focus, as many have argued, ignores other possible influences on the capacities of individuals to learn to be virtuous. Theorists from Plato and Aristotle to Marx and MacIntyre have emphasized the role of socio-political influences in inculcating virtue. The view that genes may influence how readily humans are able to learn the virtues is meant to join this chorus.” (Walker 2009, 43) There is a fundamental convergence between moral enhancement through traditional education and selecting for virtue-promoting genes. The latter supplements parenting and socialization, as well as the parent's moral duty to fostering virtuous behavior. Of course, goals are not all that matter and the dissimilarity of means cannot be overlooked (Focquaert and Schermer 2015). Even if we could one day establish a satisfactory analogy between well-designed genetic screening programs that aims at virtues and socioparental influences that instill virtue in more conventional ways, the analogy will still remain a quite limited strategy to confront the vast amount of criticism brought against moral bioenhancement in terms of safety, side effects, paternalism, individual morality, parochial and opposing moralities, and so on. In contrast, it seems that we are more willing to accept whatever parents do, as moral educators, with their children based on the assumption that they are inspired by their good will and honorable intentions.

However, the argument from similarity has some engaging effect on the debate. It fuels the idea that we should treat nonconventional moral enhancement as part of a process that is both natural and unavoidable. Eventually, we may come to the conclusion that we have to assume a positive moral obligation to (support any research that has a chance to) enhance our lives (Harris 2007, 79, 192). Why should we not extend this obligation to cover the improvement of our moral lives by enhancing moral virtues, emotions, or intuitions? Does morality not enhance our lives? While similarity of aims seems to play into the hands of moral bioenhancement supporters, it should also be the starting point to review what seems rather alarming in all appeals to moral improvement. In the next two sections, I present the alleged risk and then assess the novelty of this risk, which some fear will occur, considering three methods discussed in the literature as plausible candidates for improving peoples' morality. This line of criticism brought against moral bioenhancement relates to the danger that tools designed to improve moral conduct might (1) wrongly select out some ways of thinking and thus distort the very process of finding reasons and justifications, (2) disrupt one's narrative identity to the point of bringing about dangerous internal conflict, and (3) operate fine-tuned mental manipulations of mood and unconscious 
dispositions that would not have been endorsed by a subject who would have had the chance to properly analyze them. I have chosen these examples to illustrate how moral bioenhancement might compromise one's sense of acting as an autonomous person. However, my intention is to show that their modus operandi does not diverge from what people try to achieve through upbringing and conventional education. The argument put forward in the last section explains that precisely this similarity between new and old methods should strike us as a warning signal rather than as an incentive to pursue moral bioenhancement. One should not repeat old and familiar errors.

\subsection{Selecting for particular ways of reasoning, disruptions of one's narrative identity, and freedom from any mental manipulations}

Alterations of emotions and intuitions are one path to influence moral reasoning and decision-making. But what if special forms of moral bioenhancement would target the reasoning process itself? A great concern, for those who subscribe to the idea that there is a powerful link between reason and morality, is that moral bioenhancement could put at risk autonomous reasoning and the process of justification itself. If the means for such influence were at hand, the subject's integrity could be impaired in a pervasive manner by advocating not necessarily a substantive moral view but rather a particular way of reasoning, i.e., "the narrow conception of reasoning promoted by the enhancer” (Schaffer 2015, 270). To be sure, a moral decision will still be reached through reasoning, yet without knowing whether the reason we think it is crucial was the right reason for the matter at stake or whether the way we reach the conclusion was the soundest deduction one can provide. This is an example of how morality is bypassed by acting directly on reasoning itself. It illustrates how a person could fail without even noticing the need of analyzing his or her decisions and confronting them against the background of the assumptions. The risk is similar to the situation when someone fails to consider relevant features of a moral problem or does not take into account alternative points of view that sustain and help refine moral reasoning. It is of course a matter of pure speculation whether such unconventional tuning of high cognitive functions is possible via biochemical means or electromagnetic brain stimulation.

Another threat posed by the prospect of moral bioenhancement is the danger of causing disruptive interventions on a person's narrative identity (Focquaert and Schermer 2015). Narrative identity is defined as the sum of all features constitutive for how a person understands himself or herself and relates to his or her image. It includes experiences, attitudes, beliefs, values, and desires - in short, it is the cognitive, motivational, and emotional asset of a person. Although we define ourselves through our experiences, attitudes, and beliefs, the construction of one's self does not need to 
take place in a conscious manner. It is often the rule that we are rather unaware of how deeply rooted our natural inclinations and learned propensities are. We reach a better picture of ourselves simply by self-examination and critical exchange with friends or relatives. We testify the consistence of our self against the assumption that we are at least partially generating central pieces of our identity. Moral bioenhancement has the potential to alter this asset and to induce disrupting identity changes. This line of criticism claims that moral bioenhancement will bring about radical psychological changes that could threaten a person's sense of continuity and coherence, especially when these changes cannot plausibly be felt consistent with experiences that defined the self before the moment when the enhancement occurred. The picture becomes more intricate when such alteration of the self takes place in a quiet, unnoticed manner: "This might lead individuals to unreflectively accept or even welcome certain traits that would not be similarly endorsed by their pre-interventional/pre-enhanced self. (...) It may therefore result in a dissociation between one's implicit narrative self and one's explicit narrative self, that means: in a situation of self-blindness. (...) selfblindness, in this sense, is a form of inauthenticity that threatens the autonomy of the self" (Focquaert and Schermer 2015, 148). Thus, the objection goes on, the enhanced person must be aware of any change that attempts to reframe his or her narrative identity. One must reject interventions that bypass this awareness level as nonethical.

Drawing on a series of studies (Crockett et al. 2008, 2010) that show how serotonin modifies the subjects' moral judgments and curbs the willingness to harm others, Christoph Bublitz $(2014,2016)$ makes a plea for protecting "freedom of mind" from intrusive "alterations of unconscious dispositions". Freedom of mind is a person's capacity to make use of his or her mental functions and freely dispose of mental states "as she pleases, free from external influences and internal impediments" (Bublitz 2016, 94). In contrast to freedom of will, which is usually linked to the possibility to act otherwise, freedom of mind underlines the requirement of not being subjected to any mental manipulations, such as those described in Crockett's studies. Why would such mental freedom be ethically significant? One detrimental influence of artificially induced motivations, attitudes, or dispositions is that they might put a strain on the person's ability to consciously control his or her own mind. The effect is similar to when some unexpected noise distracts you from what you are just about to do or when you accidentally take a drug overdose with damaging effect on your normal cognitive functioning. It is not the content or the intention that is objectionable in some attempts of altering moral judgment, but rather the fact that, generally, any newly induced mental state has a diverting potential. These interventions simply consume resources and threaten to impair autonomy on the very basic level of accessing and using one's own mental power and capacity. 


\subsection{Fundamental similarity between conventional and nonconven- tional moral enhancement}

The three examples are taken from a broad and challenging range of criticisms related to moral bioenhancement. They share the concern that some interventions have the potential to undermine the link between morality and autonomous choice guided by reason in ways that could easily go unnoticed while being highly effective. If their potential is confirmed, these interventions might signal the advent of new and very powerful manipulation tools. Yet, they are in fact not so new. They are quite similar to more conventional strategies of promoting morality. In one sense, their novelty comes from the fact that, once a sufficient degree of subtlety and efficiency is attained, unconventional techniques of moral enhancement will achieve a very high resemblance with conventional means of enhancing moral judgment, as listed by some of their advocates: general education (including self-education), knowledge acquisition, introspection and disclosure of our own prejudices, engagement with genuine and urgent problems of the world, developing good policy and legislation, and so on (Harris 2011). The similarity between conventional and nonconventional moral enhancement comes from both the potential of bringing about highly effective changes and the danger of doing it in ways that may contradict morality itself. What often misfires with conventional wisdom and morality can also go wrong with moral bioenhancement, including selective endorsing of specific modes of reasoning, identity disruptions, or unnoticed alterations of one's mental life. In fact, many so-called methods of moral bioenhancement do not seem to threaten liberty, autonomy, and individuality in such a novel and overwhelming manner that no one has already seen happening during well-known stages of moral development and instruction in normal interactions between children and the adults who look after them.

Let us discuss more about this prima facie similarity between conventional and nonconventional moral enhancement. Various ways of reasoning are at work each moment we attempt to modify the others' conception on substantive issues. This is happening in everyday discussions on moral questions, as well as in highly abstract philosophical debates. When I attempt to persuade someone, my aim is not only to become the mere vehicle that passes on a substantive moral view. I will put considerable weight on passing on this view along with the right arguments, the best ways of reasoning, and the most productive strategies of backing my claims with facts. These are, as I shall think, the most appropriate means to promote the view I support. I implicitly advocate my "narrow conception of reasoning" while taking it to be the right conception of reasoning meant to secure what I consider to be the right substantive view related to a specific moral issue. Any attempt to improve moral judgment in very simple conventional ways generally promotes its underlying conception of reasoning. So, why should this feature amount to a genuine problem once moral bioenhancement becomes reality, as some critics fear? There is little sense to deplore what might go 
wrong with reasoning in moral bioenhancement if one fails to acknowledge that the suspected danger, if it really exists, should represent a concern for any other form of moral enhancement. Different forms of moral education might share the same alleged danger of selectively promoting peculiar forms of reasoning. But the willingness to overcome this danger could also be a shared feature. If the latter is true, we should simply focus on lessening the risk of any kind of biases in everyday moral reasoning, as well as in ethical debates. This includes analyzing one's decisions and confronting them against the relevant assumptions, taking into account all relevant features and views, and hoping to gradually sustain and refine moral reasoning.

The other two objections shortly described in the previous section can be considered together. According to the second objection, moral bioenhancement has the potential to severely disrupt personal identity. Artificially induced mental states might threaten a person's sense of continuity and coherence, especially when the identity shift remains undetected. While this threat seems plausible, it is, again, nothing novel. Parents teach their children the values they prize the most. They put effort and great expectation in shaping their children's identity according to what they think to be the right way of living and behave. Later on, grown-up children usually face life experiences that threaten to shake the very identity that their parents strived to polish in their preferred manner. This common test makes them reconsider parts of their most intimate beliefs. Their inner coherence holds and fails with backand-forth confirmations and refutations of what they believed to be morally right and epistemically true. Cognitive interventions that aim to modify whole systems of beliefs, such as making people more tolerant toward immigrants or more sensitive to the consequences of one's actions in a global world, work as a matter of fact by challenging deep-rooted features of their constructed and/or inherited identity. If sound moral reasoning makes people change their wrong beliefs in a process that fundamentally alters their identity, such alterations can hardly be seen as disruptive. On the contrary, they represent a move toward moral progress, indeed, an example of conventional moral enhancement. How does such enhancement actually work? In most cases, what happens is that people are confronted with facts and affirmations they are not aware of, do not want to deal with, or even intentionally disregard when they are obvious. It often means to make people acknowledge disturbing facts and put a veritable strain on their "freedom of mind", in the sense stated before as freedom from induced mental states that might have a "distracting" potential. Uncovering gross injustice or appalling cruelty can at times be very disturbing and might include and generate by itself undesired "alterations of unconscious dispositions" that challenge one's "peace of mind". Such challenges occur often as a side effect of conscious deliberation on relevant facts and issues, but they sometimes represent the method of choice for shaking a self-serving, closed system of beliefs that seems impermeable to change. In this case, the aim is to destabilize the very inner coherence that bears a protective meaning. Despite its undisclosed way of functioning and its focus on unconscious mechanisms, deliberate erosion of one's innermost freedom 
of mind is sometimes the only and the right way to make known other people's legitimate motives, interests, and goals. Raising awareness in order to better meet moral requirements that one has perhaps already endorsed is a strategy that overtly aims at disrupting, or at least challenging, one's "peace of mind" by inducing new motivations, attitudes, or dispositions. Such specific cognitive and motivational alterations, of course, consume significant psychological resources. They pose a threat to a person's capacity to freely dispose of his or her mind's integrity and autonomy at a very basic level. The question is whether we can afford to spare us such interventions in the name of a self-sufficient freedom from, as Christoph Bublitz puts it, "external influences and internal impediments".

\subsection{The constraint of moral equality between the enhancer and the enhanced person}

The purpose of these counterarguments was to show that moral bioenhancement might eventually come close to using the same paths and channeling the same resources that are involved in conventional approaches to moral enhancement. In the view of this potential similarity, it is fair to say that moral bioenhancement - at least in some of its putative forms, such as those described earlier - does not emerge as a novel risk for human autonomy. Of course, some interventions are riskier than others, and time is essential to assess the risk and overcome it. Moral bioenhancement probably has the potential to undermine values such as autonomy and liberty and provide effective means for disastrous social engineering. In other words, it can theoretically undermine or bypass morality itself. However, this cannot be a totally novel risk that takes us by surprise. Lack of critical thinking and information can easily make parenting harmful for a child's psychological integrity, turning parenting itself into a pervasive threat for autonomy later in adulthood. Unwise public policy may turn into undesirable social engineering, too. But the idea that some unconventional ways of moral enhancement (such as those described in the previous sections) are using the same paths and channeling the same resources as conventional ways (such as, let us say, when parents teach their children to be morally good persons) gives hope that same precautions might work in both areas. If this is true, we should not fear that we are not well equipped to counteract a potential danger that seems to be inherent in any attempt to promote morality, be it through conventional or nonconventional ways: the danger that enthusiasm and creative search for new means displayed in the name of moral progress might erode even the most vital moral values. We should feel at least warned by various derailments that have already occurred along so many attempts of social and moral bettering of human persons and communities. One need only think of dubious moralities embedded in cultural practices, from genderdependent assignment of roles and virtues to discrimination on various grounds. Selfawareness starts with acknowledging that the very act of caring for children and for 
one's family gives parents a powerful opportunity to choose the ways they think most appropriate to promote their values. Given this opportunity, some may choose to raise their children in ways that neglect how useful rational argumentation and empathy are at critical points in someone's life, making room for intolerance and extremism. One cannot consider this moral enhancement, even if these parents also.

To sum up, the potential danger posed by moral bioenhancement is not at all unparalleled by the danger that already exists when it comes to raising moral conscience through more conventional, e.g., cognitive, means. To be sure, what supposedly might go wrong with moral bioenhancement - the threat of fostering odd preferences for particular frames of reasoning; the prospect of profoundly transforming someone's identity; and the risk of having all kinds of "noising" input flowing into one's mental life - can as well go wrong with conventional moral enhancement, including parental education. A simple rule emerges from this similarity. One should not advocate a specific method designed to morally enhance people's conscience, motives, or behavior without giving enough guarantees that there is a way back to the current state, if the intervention proves to be unsuccessful or undesirable after up-todate and careful consideration. This possibility is there, at least theoretically, when moral enhancement targets cognitive structures. People often revise the way they have been raised by their parents through concepts and beliefs they acquire at some later stage in life. ${ }^{1}$ In contrast, this possibility, which is fundamental to the preservation of freedom and autonomy, is not at all possible for most of the popularized accounts on moral bioenhancement and, in most cases, is not even taken into account (here is an exception: Sparrow 2014). This flaw shows why some accounts are so difficult to defend. Because they focus on causal mechanisms at the biochemical or neuronal level, such accounts are constrained to measure their success in terms of output stability. They do not treat the subjects of potential interventions as dynamic entities but rather as fixed structures that can be made to fit in a devised scheme. The will of the designer prevails over the latent qualities and abilities of the designed subject.

Nevertheless, why should we defend the right to revise and invalidate an intervention that makes changes for the better even when we could reach absolute confidence that the change is beneficial for the subject (similar to so many parental influences that bring about positive changes in children)? Part of the answer has to do

1 This seems to me the kind of statement anyone would find best illustrated by examples taken from his or her own experience. Yet, if we do not want to get caught in the deep waters of any old and new empirical research, one will find similar insights from rather unexpected intersections of theoretical accounts. Drawing on Freud's views on parental authority and its role in moral learning, John Rawls agrees that "since parents and others in authority are bound to be in various ways misguided and self-seeking in their use of praise and blame, and rewards and punishments generally, our earlier and unexamined moral attitudes are likely to be in important respects irrational and without justification. Moral advance in later life consists partly in correcting these attitudes in the light of whatever principles we finally acknowledge to be sound.” (Rawls 1999, 402) 
with preserving freedom and autonomy. It is also a question of moral equality. It might be useful to recall in this context a similar worry that emerged about 2 decades ago around reprogenetics and positive eugenics. The prospect of combining reproductive and genetic technologies in order to single out desired physical or psychological traits raised concerns that more and more would-be parents will be tempted to genetically enhance their offspring. Of course, many projections extensively discussed in the literature remain even today pure possibilities. However, the ethical debate captured an essential aspect touching core values in a liberal society: the idea that people form a moral community of free and equal persons, an idea that spans a wide tradition of liberal thinking, starting with John Locke and reaching its highlight with John Rawls. In a 2001 lecture, Jürgen Habermas worked out an argument against liberal eugenics. It reads as follows: Any parent-child relationship is inevitably asymmetrical. In normal socialization processes, parents exercise a vast influence over their children. A parent's goals and expectations, as well as the means chosen to fulfill them, do sometimes match and sometimes do not match future self-assumed intentions, goals, means, and expectations of grown-up children. Still, the risk of dissonant cases is compensated by the fact that whatever influence parents exert over their offspring, this influence is essentially open to question. As Habermas put it, children "can retrospectively compensate for the asymmetry of filial dependency by liberating themselves through a critical reappraisal of the genesis of such restrictive socialization processes" (Habermas 2003, 62). By critically reassessing the life projects their parents specially devised for them, children acquire the status of free and equal persons transgressing intergenerational boundaries.

However, reassessment of goals and means is no longer possible for people selected via genetic programming for some specific traits and dispositions:

Eugenic interventions aiming at enhancement reduce ethical freedom insofar as they tie down the person concerned to rejected, but irreversible intentions of third parties, barring him from the spontaneous self-perception of being the undivided author of his own life. [...] A universalistic understanding of law and morality rests on the assumption that there is no definite obstacle to egalitarian interpersonal relations. [...] No dependence on another person must be irreversible. [...] Eugenic programming establishes a permanent dependence between persons who know that one of them is principally barred from changing social places with the other. But this kind of social dependence, which is irreversible because it was established by ascription, is foreign to the reciprocal and symmetrical relations of mutual recognition proper to a moral and legal community of free and equal persons. (Habermas 2003, 63-5)

The asymmetrical relationship between an enhancer and the enhanced is obvious in both trait selection via genetic programming and moral enhancement through different methods that aim at modulating emotions, attitudes, or behavior. One does not need to embrace Habermas's account of communicative action as a foundation of any interaction in order to see how basic human relationships might irreversibly shift. However, these observations make a plea for disclosing what normative concept 
of human person and humanity one chooses when it comes to assessing whether the shift takes place in the right direction or not. For Habermas, this normative concept is the idea of free and equal persons.

Here is an illustration from another field. When John Rawls describes what psychological constraints should form the basis for assessing the reasonableness of a theory of justice, he embarks on his favorite constructivist approach and outlines a moral psychology that fits the task. He constructs persons through the lens of their two moral powers. These are assumptions that lead to the preferred concept of person around the idea of moral equality. No reasonable conception of justice can bypass this concept and overlook the fact that people enjoy equal moral status. To hold on the concept of moral equality is a normative assumption. As Rawls $(1993,87)$ put it in Political Liberalism: "Human nature and its natural psychology are permissive: they may limit the viable conceptions of persons and ideals of citizenship, and the moral psychologies that may support them, but do not dictate the one we must adopt."

Now, any advocate of moral bioenhancement should assess the recommended method from a similar line of reasoning. The analogy is straightforward. The first question one should ask is: Does this particular method of morally enhancing people's intentions, emotions, attitudes, or behavior have the potential of asymmetrically shifting the relationship between free and equal persons? The second question would be: Is there any guarantee that the designed intervention to morally enhance people's intentions, emotions, and so on can be critically revised and undone if it proves unacceptable from the subject's perspective? This question is important as a check against the fundamental asymmetry between the enhancer and the enhanced subject. The enhancer must ensure that the person enhanced can reverse the intervention, if he or she finds it wrong. The second question cannot be dismissed by showing that the proposed intervention is morally good beyond any doubt and that no one will ever be able to consider it unacceptable. Their status as free and equal persons is at stake before and after the intervention. Both parties agree that it is a requisite for a moral life to preserve their reciprocal recognition as free and equal members of a moral community. Should moral bioenhancement generate a longlasting imbalance detrimental for this kind of recognition between free and equal persons, it will compromise morality itself. Traditional means of moral enhancement are not essentially different compared to unconventional means from the perspective captured in the first question. Various forms of raising awareness for any kind of moral values and goals, work often, whether during childhood or later in life, through persuasion, rational constraints, and generally by guiding the moral subject. They could sometimes amount to a veritable sort of "maneuvering" of the subject toward the correct belief or behavior. Such interventions are, to a certain degree, similar to objectifying a person and his or her will to a greater aim. Thus, it will be a mistake not to see that nearly any common interactions between an educator and his or her pupil bear the potential of bringing about the same imbalance concerning their status as 
free and equal persons we fear from unconventional moral enhancement. Here too, it is true that preserving moral equality is a requisite for a moral life.

\section{References}

Bublitz, Christoph. 2016. “Moral Enhancement and Mental Freedom.” Journal of Applied Philosophy 33(1): 88-106.

DeGrazia, David. 2014. “Moral Enhancement, Freedom, and What We (Should) Value in Moral Behavior." Journal of Medical Ethics 40(6): 361-368.

Douglas, Thomas. 2008. “Moral Enhancement.” Journal of Applied Philosophy 25(3): 228-245.

Douglas, Thomas. 2013. "Moral Enhancement via Direct Emotion Modulation: A Reply to John Harris.” Bioethics 27(3): 160-168.

Focquaert, Farah, and Maartje Schermer. 2015. “Moral Enhancement: Do Means Matter Morally?” Neuroethics 8(2): 139-151.

Habermas, Jürgen. 2003. The Future of Human Nature. Cambridge: Polity Press.

Harris, John. 2007. Enhancing Evolution. The Ethical Case for Making Better People. Princeton, NJ: Princeton University Press.

Harris, John. 2011. “Moral Enhancement and Freedom.” Bioethics 25(2): 102-111.

Harris, John. 2014. “Taking Liberties with Free Fall.” Journal of Medical Ethics 40(6): 371-374.

Harris, John. 2016. “Moral Blindness - The Gift of the God Machine.” Neuroethics 9(3): 269-273.

Persson, Ingmar, and Savulescu, Julian. 2008. "The Perils of Cognitive Enhancement and the Urgent Imperative to Enhance the Moral Character of Humanity." Journal of Applied Philosophy 25(3): 162-177.

Persson, Ingmar, and Julian Savulescu. 2013. "Getting Moral Enhancement Right: The Desirability of Moral Bioenhancement.” Bioethics 27(3): 124-131.

Persson, Ingmar, and Julian Savulescu. 2016. "Moral Bioenhancement, Freedom and Reason.” Neuroethics 9(3): 263-268.

Rawls, John. 1993. Political Liberalism, 2nd ed. 1996. Cambridge, New York: Columbia University Press.

Rawls, John. 1999. A Theory of Justice. Rev. ed. Cambridge, Massachusetts: Belknap Press.

Schaefer, G. Owen. 2015. "Direct vs. Indirect Moral Enhancement.” Kennedy Institute of Ethics Journal 25(3): 261-289.

Sparrow, Robert. 2014. "Better Living Through Chemistry? A Reply to Savulescu and Persson on 'Moral Enhancement'.” Journal of Applied Philosophy 31(1): 23-32.

Walker, Mark. 2009. “Enhancing Genetic Virtue: A Project for Twenty-first Century Humanity?” Politics and the Life Sciences 28(2): 27-47. 